\title{
Minor Response
}

National Cancer Institute

\section{Source}

National Cancer Institute. Minor Response. NCI Thesaurus. Code C123598.

Some response with no new symptoms or disease and not meeting partial response. 